\title{
Compensatory and Learning Strategies of Cit Students: Tools in Improving Listening Abilities
}

\author{
Warlito M. Galita \\ College of Industrial Technology, Bulacan State University, Malolos, Philippines \\ Email: chloky23@yahoo.com
}

Received 20 February 2015; accepted 8 March 2015; published 12 March 2015

Copyright (C) 2015 by author and OALib.

This work is licensed under the Creative Commons Attribution International License (CC BY). http://creativecommons.org/licenses/by/4.0/

(c) †) Open Access

\section{Abstract}

The objective of this study is to determine the learning and compensatory strategies the College of Industrial Technology (CIT) students use to enhance their listening skills and the various strategies that these learners use to compensate their limited skills and abilities. Findings reveal that the student-respondents exhibited the (10) learning and compensatory strategies of study, concentration, memory, learning from textbooks, learning from lectures, essays and assignments, exams, organization and time management, self-advocacy skills and disability specific strategies to a moderate degree. In addition, majority of the student-respondents were only able to obtain low scores in their listening tests. Regarding the correlations, it was found that out of the $10 \mathrm{com}$ pensatory learning strategies, four were found to have correlation with listening abilities. Study strategies and learning from lectures were found to have high significant correlation with listening abilities while memory as well as organization and time management had significant relationship with listening abilities. All in all, these findings lead to the decision to reject the hypothesis of the study that states that there is no significant relationship between student-respondents' compensatory learning strategies and their listening abilities.

\section{Keywords}

Learning and Compensatory Strategies, English, Listening Abilities

Subject Areas: Education

\section{Introduction}

English is widely considered universal language of commerce, science and diplomacy. It is the window to the world's treasure house of knowledge. Official documents, particularly laws and court decisions are in the English 
language. Communication skills in English can go a long way in helping young individuals become successful in the highly competitive fields of business, industry and most especially in technology, or in increasing their chances of employment locally and internationally.

It has been recognized that the Philippines has the largest number of overseas Filipino workers deployed in different countries. This creates greater demands for the work force to develop high-leveled English language skills for business communication. Such demand can be seen in business organizations requiring their employees to have highly functional language skills to be able to perform their business efficiently. Many jobs require the applicants to be fluent in English. These facts clearly underscore the importance of knowledge of English as a second language is a requirement in these times.

Corollary to this idea, students' language ability is also related to academic success [1]. This puts a big burden on the educational system to develop students who have a good grasp of the English language, that is, it translates to the satisfactory communicative competence of the individual.

One important objective of language teaching is to develop the communicative competence of learners. Whenever language proficiency is addressed in the English classroom, both language and content area teachers face problems regarding the use of English as the students' medium of communication particularly the students' inability to express themselves orally. It has been observed that when learners are asked to explain, discuss, converse or ask questions in English, they frequently stop speaking because they hardly know what to say.

According to Nunan [2], listening is the Cinderella skill in second language learning. All too often, it has been overlooked by its eldest sister, speaking. For most people, being able to claim knowledge of a second language means being able to speak and write in that language. Listening and reading are therefore secondary skills, means to other ends, rather than ends in themselves. To cope, second language learners need to employ different learning and compensatory strategies to be able to go on in any communicative situation.

But what are learning strategies? Strategies are the mental and communicative procedures learners use in order to learn and use language. Underlying every learning task is at least one strategy. However, in most classrooms, learners are unaware of the strategies underlying the learning tasks in which they are engaged in.

According to Oxford's taxonomy, there are two main types of language learning strategies: the direct strategies and the indirect strategies. Among the direct strategies are compensatory strategies that "enable learners to use the new language for either comprehension or production despite limitations in knowledge" [3].

This fueled the burning desire of the researcher to investigate the learning and compensatory strategies that students employ in enhancing their English language proficiency, particularly their listening abilities. The present study aimed to identify the compensatory strategies frequently used by College of Industrial Technology (CIT) students in the Bulacan State University (BSU) and correlate them with student-related factors and their grade in English. The results of this investigation may help English teachers in enhancing their students' English language proficiency and eventually make them participating individuals in the language classroom as they use efficient compensatory strategies.

\section{The Research Problem}

The general problem of the study is: What learning and compensatory strategies do students use to enhance their listening abilities?

Specifically, the study sought to answer to the following questions:

1) To what degree do the student-respondents use the learning and compensatory strategies to offset their limited listening abilities?

2) What are their scores in a listening test?

3) Is there a significant correlation between learning and compensatory strategies and the respondents' listening skills?

4) What are the implications of the results of the study for teaching skills to ESL students?

5) What listening intervention program needs to be developed in the light of the results of the study?

\section{Methodology}

The conceptual framework of this study is shown in Figure 1. The conceptual model of the study consists of two (2) frames; the first frame shows the independent variables (IV), while the second frame presents the dependent variable (DV). 


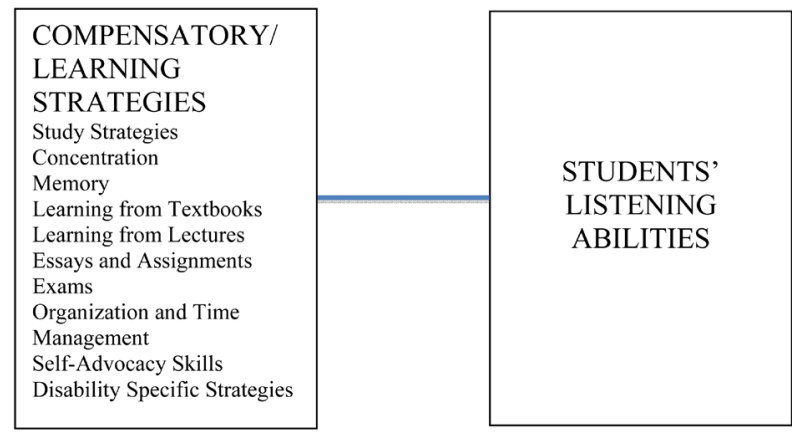

Figure 1. Conceptual framework.

The first frame presents the independent variables which consist of the following students' compensatory learning strategies namely; Study Strategies, Concentration, Memory, Learning from Textbooks, Learning from Lectures, Essays and Assignments, Exams, Organization and Time Management, Self-Advocacy Skills and Disability Specific Strategies. On the other hand, the second frame presents the dependent variable of the study, which is the student's listening abilities. The line connecting the first frame (IV) and the second frame (DV) indicates the hypothesized relationship of the independent variables on the dependent variable.

The following hypothesis was formulated to be tested for rejection or acceptance:

There is significant relationship that exists between the subject-respondents' listening skills and their compensatory learning strategies.

The study utilized the descriptive method of research. A descriptive study describes and interprets. It relates to conditions or relationships, opinions held and processes going on, effects that are evident or trends that are developing. It is primarily concerned with the present, although it often considers past events and influences as they relate to current conditions [4].

Two (2) standardized questionnaires were used in this study. One is the Learning and Compensatory Strategies Inventory Checklist developed by Herriot [5] and University of Cambridge ESOL Examinations Listening Test [6]. These 2 instruments were used as the primary source of data for the study. These instruments were used to gather data for describing the respondents' compensatory strategies as well as their listening skills.

The researcher personally administered the instruments to the respondents. The respondents of the study involved 156 freshmen students representing 20\% of the total first year CIT population from the BSU Main Campus during the school year 2013-2014. The Learning and Compensatory Strategies Inventory Checklist was administered to the respondents under the usual and ordinary testing conditions so as to give enough time for them to answer the questions. The personal data and demographic profile of the respondents were presented using frequency and percentage. Meanwhile, the perceptions of the student respondents regarding the learning and compensatory strategies were presented using the weighted mean and standard deviation.

5-To a Very Large Degree (VLD)

4-To a Large Degree (LD)

3-To a Moderate Degree (MD)

2-Only Slightly (OS)

1 -Not at All (NA)

On the other hand, the scores in the listening test will be interpreted as follows:

$25-30$

Very High

$19-24 \quad$ High

$13-18 \quad$ Average

$7-12 \quad$ Low

6 and below Very Low

Finally, the significant relationships among the variables were ascertained using Pearson Correlation and Test of Significance.

\section{Results and Discussion}

This part presents, analyzes, and interprets the gathered data for the purpose of ascertaining the various learning 
and compensatory strategies students use to enhance their listening abilities. For better understanding and interpretation of the data, the presentation is done part by part in accordance to the specific problems presented earlier.

\section{1) Student-Respondents Profile}

Out of all the CIT student-respondents, two-thirds are males while the rest are females. It was also observed that a great majority of the student-respondents' come from poor families as reflected in their monthly income.

\section{2) Student-Respondents' Learning and Compensatory Strategies}

All in all, the data in Table 1 show that the CIT student-respondents exhibited the ten (10) learning and compensatory strategies of study, concentration, memory, learning from textbooks, learning from lectures, essays and assignments, exams, organization and time management, self-advocacy skills and disability specific strategies to a Moderate Degree.

\section{3) Students' Scores in the Listening Test}

Results shown in the table below (Table 2) revealed that majority of the CIT student-respondents were not able to obtain even a passing score in their listening test, thus registering low scores.

\section{4) Relationship of Student Respondents' Compensatory Learning Strategy to Their}

\section{Listening Ability}

Out of the 10 compensatory learning strategies, four (4) were found to have correlation with listening abilities. Study strategies and learning from lectures were found to have high significant correlation with listening abilities while memory as well as organization and time management had significant relationship with listening abilities.

Study Strategies. It can be gleaned from Table 3 that study strategies is correlated with students listening abilities, as indicated by the computed Pearson $r$ of 0.460 which is significant at 0.01 level. This means that with every unit increase in effective study strategies, there is also a slight increase in listening abilities.

\section{Table 1. Summary table of student respondents' learning and compensatory strategies.}

\begin{tabular}{ccc}
\hline Learning and Compensatory Strategies & Overall Mean & Verbal Interpretation \\
\hline Study Strategies & 3.37 & To a Moderate Degree \\
Concentration & 3.24 & To a Moderate Degree \\
Memory & 3.33 & To a Moderate Degree \\
Learning from Textbooks & 3.34 & To a Moderate Degree \\
Learning from Lectures & 3.36 & To a Moderate Degree \\
Essays and Assignments & 3.20 & To a Moderate Degree \\
Writing Tests and Exams & 3.33 & To a Moderate Degree \\
Organization and Time Management & 3.32 & To a Moderate Degree \\
Self-Advocacy & 3.26 & To a Moderate Degree \\
Disability-Specific Strategies & 3.21 & To a Moderate Degree \\
Grand Mean & $\mathbf{3 . 3 0}$ & To a Moderate Degree \\
\hline
\end{tabular}

Table 2. Student respondents' scores in the listening test.

\begin{tabular}{ccccc}
\hline Intervals & Frequency & Percent & Mean Score & VI \\
$0-2$ & 37 & 23.72 & & ..13 \\
$3-5$ & 80 & 51.28 & Very Low \\
$6-8$ & 34 & 21.80 & & \\
$9-11$ & 5 & 3.20 & \\
\hline
\end{tabular}


Table 3. Relationship of student compensatory learning strategies and their listening ability.

\begin{tabular}{cc}
\hline Compensatory Learning Strategies & Correlation \\
\hline Study Strategies (SS) & Students' Listening Abilities (SLA) \\
Concentration (Con) & $0.339^{* *}$ \\
Memory (M) & 0.146 \\
Learning from Textbooks (LFT) & $0.173^{*}$ \\
Learning from Lectures (LFL) & 0.154 \\
Essay and Assignments (EA) & $0.460^{* *}$ \\
Exams (Ex) & 0.103 \\
Organization and Time Management (OTM) & 0.107 \\
Self-Advocacy Skills (SAS) & $0.158^{*}$ \\
Disability Specific Strategies (DSS) & 0.135 \\
\hline
\end{tabular}

"Correlation is Significant at the 0.05 level (2-tailed); ${ }^{* *}$ Correlation is Significant at the 0.01 level (2-tailed).

Language learning strategies are special ways to help people to realize, to learn new knowledge. As an old Chinese saying goes "Teaching a man how to fish is better than giving him a fish." Teachers cannot always teach him by his side throughout his life, so these strategies play an important role in developing learner autonomy. Furthermore, Reis et al. [7] noted that study strategies comprise a vital component of the compensation strategies that are very important for these adult learners. In a comprehensive study of learning specialists' logs that recorded the activities of sessions with university students with learning disabilities, Hopper [8] found specific areas commonly addressed in a successful university program for students with learning disabilities. These included study strategies, course-related performance strategies (e.g., reading comprehension and written expression), counseling, and self-advocacy training.

Learning from Lectures. A closer look at the numerical figures reflected in Table 3, showed that learning from lectures is correlated to students' listening abilities as indicated by a correlation coefficient $r$ equal to 0.460 which is significant at 0.01 level (2-tailed test).

Charlton [9] stated that lectures are probably the best teaching method in many circumstances and for many students; especially for communicating conceptual knowledge, and where there is a significant knowledge gap between lecturer and audience.

However, the lack of a convincing rationale has been a factor in underestimating the importance of lectures and there are many who advocate their replacement with written communications or electronic media. He suggests that lectures are effective because they exploit the spontaneous human aptitude for spoken (rather than written) communications and because they are real-time, human-presence social events (rather than electronic media).

In a nutshell, lectures retain a major educational role because they exploit evolved aspects of human nature to make learning easier and more effective when compared with electronic and literacy-based media. And, as teaching especially in higher education continues to expand, it is important to make learning as easy as possible. So instead of trying to phase-out lectures, teachers in English should strive to make them better. To do this entails understanding how lectures exploit human psychology-especially the fact that lectures are essentially formal, spoken, social events.

Memory. Further perusal of Table 3 revealed that memory is correlated to students' listening abilities as indicated by a correlation coefficient $r$ equal to 0.173 which is significant at 0.05 level (2-tailed test).

Memorization is about reproducing information while understanding and is about being able to remember information so that one can build meaning, seek relevance, and discover relationships and applications. These are effective learning strategies if the purpose is to memorize material and they work best if the purpose is to understand. It is also important to know what they are, how to use them and when to use them. According to Richards 
[10] memory strategies can be used in many different ways. They can be used to introduce a concept in a way that will stick and provide a palette for the student to use as he works to expand his understanding of the concept.

Strategies can also be used to reinforce a concept in a way that provides a tool to help the student retrieve the known information. Many of these strategies use a technique called mnemonics, which are basically "memory tools.” Mnemonics can help capture information for later retrieval because they help the student form a pattern. An overall goal for students is to develop automatic strategy use, as this increases efficiency when learning and studying. Initially some strategies may take more time for students and they may be hesitant to spend the extra time. But eventually they will find that the use of strategies enhances their ability to organize and retrieve the information, consequently increasing learning efficiency.

Organization and Time Management. Finally, the same table showed that organization and time management is correlated to students' listening abilities as indicated by a correlation coefficient $r$ equal to 0.158 which is significant at 0.05 level (2-tailed test).

Firchow [11] stated that there seem to be so many demands on everyone's time and energy these days. Everyone is busy, and unfortunately, learners aren't born knowing how to manage time and organize their materials. Learners with learning disabilities (LD) often have an even harder time learning how to get and stay organized and meet deadlines. It is in this vein that teachers can help by teaching your child strategies that make staying organized easier and by setting a good example. One may sit down with learners to examine how they spend their time, including school, sleep, meals, sports practice, homework time, social activities, religious study, etc.

These ideas are in line with the ideas of Reis et al. [7] who found that time management was the most frequently occurring objective among study strategies. The use of one-month organizers and semester overview calendars was consistently modeled and further enhanced by analyzing each week, and sometimes each day, to maximize the students' use of time. Time management has been found to depend on students' abilities to selfmonitor their activities and make appropriate decisions based upon awareness of the extra time required to complete academic tasks in the area of the specific disability.

\section{Conclusions}

On the basis of the findings, the following conclusions are drawn:

1) There is a high significant correlation among study strategies as well as learning from lectures and listening abilities.

2) There is a significant correlation between memory as well as organization and time management and listening abilities.

All in all, these findings lead to the decision to accept the hypothesis of the study that states that there is a significant relationship between student-respondents' compensatory learning strategies and their listening abilities.

\section{Recommendations}

On the basis of the significant findings and conclusions of this study, the following are posited as the recommendations:

1) The school should sponsor workshops, seminars and symposiums regarding learning and compensatory strategies in language education so as to maximize both students and teachers' participation and exposure to the said activities at least once a year.

2) The teachers should continue to upgrade their professional qualifications to keep them abreast with the latest developments in language education, thereby keeping themselves prepared in the hard task of educating the youth.

3) The teachers should introduce different kinds of strategies to suit students with different needs and abilities. In so doing, the students should be motivated to manifest positive values acquired in school, in various socioeducational activities in school, at home and in the community.

4) That further exploration of these compensatory learning strategies and its relationship to listening abilities must be done in order to give invaluable implications to the English teachers and policy makers in drafting the course content for the language subjects in the CIT program.

5) Finally, insofar as the findings showed that the student respondents were not even able to obtain even a 
passing score in their listening test, it is also recommended that the subject-respondents who were diagnosed to have poor listening abilities must undergo an intervention program in improving listening abilities. The proposed program, called "Listening Skill Intervention Service" or LSIS will be adapted by the researcher to provide service that will enhance the aural communication skills of the students.

\section{References}

[1] Johnson, K. (2008) An Introduction to Foreign Language Learning and Teaching. 2nd Edition, Pearson, Harlow.

[2] Nunan, D. (2009) Second Language Teaching and Learning. Cengage Learning Asia, Pte. Ltd., Vancouver.

[3] Oxford, R.L. (1990) Language Learning Strategies: What Every Teacher Should Know. Newburry House, New York.

[4] Best, J.W. and Kahn, J.V. (1998) Research in Education. 8th Edition, Butler University, Emeritus, University of Illinois, Chicago.

[5] Herriot, C. (1999) Learning and Compensatory Strategies Inventory Checklist. Centre for Students with Disabilities. University of Guelph, Guelph.

[6] University of Cambridge ESOL Examinations Listening Test.

[7] Reis, S.M., McGuire, J.M. and Neu, T.W. (2000) Compensation Strategies Used by High-Ability Students with Learning Disabilities Who Succeed in College. National Association of Gifted Children, Gifted Child Quarterly, 44, 123-134. http://dx.doi.org/10.1177/001698620004400205

[8] Hopper, C. (2013) Practicing College Learning Strategies. 6th Edition, Houghton Mifflin Co., New York.

[9] Charlton, B.G. (2006) Lectures Are an Effective Teaching Method Because They Exploit Human Evolved "Human Nature” to Improve Learning-Editorial. Medical Hypotheses, 67, 1261-1265. http://dx.doi.org/10.1016/j.mehy.2006.08.001

[10] Richards, R. (2008) Memory Strategies for Students: The Value of Strategies. http://www.ldonline.org/article/5736/

[11] Firchow, N. (2013) Organization and Time Management Strategies for Kids with LD. http://www.greatschools.org/special-education/support/757-organization-time-management-strategies-kids-with-ld.gs? page $=2$ 